EGU2020-4577

EGU General Assembly 2020

(c) Author(s) 2020. This work is distributed under

the Creative Commons Attribution 4.0 License.

\title{
"In situ" characterization of the sedimentary record and structures using Virtual Reality: new insights from the Kimberley outcrop (Gale Crater, Mars)
}

Gwénaël Caravaca, Nicolas Mangold, Stéphane Le Mouélic, Laetitia Le Deit, and Marion Massé CNRS, UMR 6112 CNRS Laboratoire de Planétologie et Géodynamique Nantes, Nantes, France (gwenael.caravaca@univnantes.fr)

Since 2012, the Mars Science Laboratory Curiosity rover has studied the sedimentary deposits within the Gale Crater, leading to the description of varying lacustrine to fluviatile and fluvio-deltaic environments. Here, we focus on the sedimentary record of the Kimberley outcrop traversed by Curiosity between sols 603 and 630 . This section presents siliciclastic rocks with an unusually high potassic content (Le Deit et al., 2016, JGR-Planets). However, poorly constrained architecture and stratigraphic relations between the series of the Kimberley Formation and their local to regional surroundings still prevent further understanding of the exact extent of these accumulations and their significance within the broader Gale Crater paleoenvironmental scheme.

Such questions highlight the need for a new finer mapping of the area to characterize the contacts observed on the outcrop itself and in its immediate vicinity, but also for a new assessment of the precise nature and morphology of the sedimentary structures and their spatio-temporal distribution throughout the outcrop and beyond.

We therefore propose to use a true color highly resolved Digital Outcrop Model (DOM) of the Kimberley outcrop, obtained using Mars Science Laboratory imagery, integrated into a Virtual Reality (VR) environment (Caravaca et al., in press, PSS). Taking advantage of this "in situ" geological analysis of the DOM, we were able to observe and characterize such sedimentary structures and contacts, as well as their spatial extension throughout the reconstructed area of Kimberley with an unprecedented precision. We notably observe and describe both conformable and unconformable contacts over the entire outcrop, but also several sets of varying scale crossstratifications (from $\mathrm{cm}$ - to pluri-meter scale). These results are in accordance with a fluviatile hydrodynamically active system. They tend to corroborate the idea of a complex yet diachroneous evolution of the area, with the possibility of laterally evolving depositional settings, spanning a significant amount of time. 